This article was published in International Journal of Hydrogen Energy, 39 (35), 19970-19981, 2014 http://dx.doi.org/10.1016/j.ijhydene.2014.10.029

\title{
Study of Different Designs of Methanol Steam Reformers: Experiment and Modelling
}

\author{
P. Ribeirinha ${ }^{1}$, M. Boaventura ${ }^{1}$, J. C. Lopes ${ }^{2}$, J. Sousa ${ }^{1,3}$, A. Mendes ${ }^{1, *}$
}

\begin{abstract}
${ }^{1}$ LEPABE - Laboratório de Engenharia de Processos, Ambiente e Energia, Faculdade de Engenharia, Universidade do Porto, Rua Dr. Roberto Frias s/n, 4200-465 Porto, Portugal

${ }^{2}$ Laboratório de Processos de Separação e Reação (LSRE), Faculdade de Engenharia do Porto, Rua Roberto Frias, 4200-465 Porto, Portugal

${ }^{3}$ Departamento de Química, Escola de Ciências da Vida e do Ambiente, Universidade de Trás-os-Montes e Alto Douro, Quinta de Prados, 5000-801 - Vila Real, Portugal

* Corresponding author. Tel.: +35122 5081695; fax: +35122508 1449

E-mail address: mendes@fe.up.pt (A. Mendes).
\end{abstract}

\begin{abstract}
Three reformers with different designs (multi-channel, radial and tubular) were developed for thermal integration with a high temperature polymeric electrolyte membrane fuel cell (HT-PEMFC). They were characterized experimentally at temperatures between $443 \mathrm{~K}$ and $473 \mathrm{~K}$, using the commercial catalyst G66 MR from Süd-Chemie $\left(\mathrm{CuO} / \mathrm{ZnO} / \mathrm{Al}_{2} \mathrm{O}_{3}\right)$. The reactors were modelled and simulated using a computational fluid dynamics (CFD) analysis. The models were validated using experimental data.

The results showed that the multi-channel design is the best solution for thermal integration with a HT-PEMFC, presenting high methanol conversion and low pressure drop. Regarding the heat transfer ability, the multi-channel showed also the best performance, presenting the lowest temperature sink among the studied reformers. The low flow velocities and the absence of metallic surfaces in the radial reformer had detrimental effect on the heat transfer. Concerning the flow distribution a coefficient of variation of $0.6 \%$ was observed in the multichannel reformer. A quasi plug flow behavior was found in the tubular and a multichannel (channels region only) reformer, while in the radial a not fully developed laminar flow was found.

At temperatures lower than $473 \mathrm{~K}$ was found that the reformate stream did not require further purification to be fed to a HT-PEMFC due to the low CO concentration $(<1600 \mathrm{ppm})$.

The advantages and limitations of each design is discussed based on experimental data and CFD modeling.
\end{abstract}

Key words: Radial, tubular, multi-channel, reactor, CFD, reforming 


\section{Introduction}

Polymer electrolyte membrane fuel cells (PEMFC) are compact electrochemical devices that convert chemical into electrical energy in an efficient way. They require high purity hydrogen as a feeding fuel, especially with very low carbon monoxide content. Hydrogen, however, has a very low volume energy density and shows limitations regarding storage and transportation. To overcome these challenges, in-situ hydrogen production from fuels such as methane, methanol or ethanol is being considered. Methanol under standard conditions has a much higher volume energy density $\left(1.8 \times 10^{4} \mathrm{~kJ} \cdot \mathrm{dm}^{-3}[1]\right)$ than hydrogen $\left(13 \mathrm{~kJ} \cdot \mathrm{dm}^{-3}[1]\right)$ and it is easier to handle, store and particularly due to absence of $\mathrm{C}-\mathrm{C}$ bonds has a low reforming temperature (513 K - 533 K).

The integration of in-situ hydrogen production by methanol steam reforming (MSR) with HT-PEMFC is already used in power supplies manufactured by few companies such as Ultracell [2], AixCellSys [3] and Serenergy [4]. In most cases, as the power supplies developed by the previous companies, the MSR reactor operates as a standalone device (external reforming) [5]. It presents the advantage of not being restricted to the fuel cell stack configuration, allowing different arrangements reformer/fuel cell and higher operation temperature. As a drawback, external reforming does not take the advantage of the heat released in the electrochemical reaction for the reforming reaction.

\section{Advantages of internal reforming}

Methanol steam reforming (MSR) reaction occurs simultaneously with two secondary reactions, water gas shift (WGS) and methanol decomposition (MD), as described below:

$$
\begin{array}{lll}
\text { (MSR) } & \mathrm{CH}_{3} \mathrm{OH}+\mathrm{H}_{2} \mathrm{O} \square \quad \mathrm{CO}_{2}+3 \mathrm{H}_{2} & \Delta H^{\circ}{ }_{298 \mathrm{~K}}=+49.7\left(\mathrm{~kJ} \cdot \mathrm{mol}^{-1}\right) \\
\text { (WGS) } & \mathrm{CO}+\mathrm{H}_{2} \mathrm{O} \square \quad \mathrm{CO}_{2}+\mathrm{H}_{2} & \Delta H^{\circ}{ }_{298 \mathrm{~K}}=-41.2(\mathrm{~kJ} \cdot \mathrm{mol}-1) \\
\text { (MD) } & \mathrm{CH}_{3} \mathrm{OH} \square \quad \mathrm{CO}+2 \mathrm{H}_{2} & \Delta H^{\circ}{ }_{298 \mathrm{~K}}=+90.7(\mathrm{~kJ} \cdot \mathrm{mol}-1)
\end{array}
$$

A fuel cell is an exothermic device that wastes ca. $50 \%$ of the input chemical energy while MSR reaction is endothermic. The integration of a cellular methanol steamreforming reactor (MSR-C) intercalated with a PEMFC in a stack arrangement, in order to take advantage of this synergetic effect, should be a very advantageous approach. However, fuel cells operate typically at around $363 \mathrm{~K}$ (LT-PEMFC) or $443 \mathrm{~K}$ (HT-PEMFC), and a MSR operates at $523 \mathrm{~K}$. Due to this operating temperature mismatching, many 
authors have chosen to study the two systems in a separated way. But, if the operation temperature of the FC (HT-PEMFC) is increased and the operating temperature of the MSR $[6,7]$ is decreased, internal integration would be possible. The two systems should operate at temperatures ca. $453 \mathrm{~K}$, but for this arrangement a more active catalyst is required. At $453 \mathrm{~K}$, the conversion of the commercial catalyst $\mathrm{CuO} / \mathrm{ZnO} / \mathrm{Al}_{2} \mathrm{O}_{3}$ for a $m_{\text {cat }} / F_{\text {MeOH }}$ of $30 \mathrm{~kg} \cdot \mathrm{s} \cdot \mathrm{mol}^{-1}$ is around $13 \%$ [8]. To obtain an acceptable methanol conversion (>95\%) at this temperature, larger amounts of catalyst are required.

The thermal integration of MSR/HT-PEMFC was first investigated by Pan et al. [6], who studied the performance of a two-cell stack (HT-PEMFC) coupled with a reformer operating at temperatures between $453 \mathrm{~K}$ and $473 \mathrm{~K}$. However, the heat required to carry out the MSR reaction was not coming exclusively from the electrochemical reaction, but also from electrical heaters.

Avgouropoulos et al. [7, 9] proposed a direct internal reforming setup, coupling the electrochemical reactions and the MSR reaction at the FC anode chamber. The reaction was carried out between $473 \mathrm{~K}$ and $483 \mathrm{~K}$ using a PEM from ADVENT TPS, and a $\mathrm{CuMnO}_{\mathrm{x}}$ reforming catalyst. This application allowed a continuous electrochemical hydrogen removal from the reforming reaction, enhancing the methanol conversion. However, the membranes showed to be intolerant to the high methanol concentrations, resulting in low power output [9].

The thermal integration of a MSR-C with a FC in a stack arrangement relies on the catalyst activity at low temperatures; nevertheless a new generation of catalysts for low temperature methanol steam reforming (LT-MSR) is expected to overcome this issue [10]. Design of the Reformers

To achieve an efficient integration of MSR/HT-PEMFC, the reformer must be optimized to maximize the heat transfer with a uniform flow distribution and low pressure drop. Typically the MSR reaction is carried out in a tubular packed bed reactor, due to its simplicity and low cost. However, well-structured flat micro or mini reactors are more suitable and present advantages, such as higher surface-to-volume ratio, better heat and mass transfer properties and flow patterns that fit with the reaction needs [11].

Most studies describing well-structured flat reactors for MSR reaction have flow fields based on single channel design or based on a series of parallel channels, as discussed below.

\section{Single channel reformers}

Different reformer designs, such as coil-shaped or serpentine-shaped, can be obtained from a single channel design. The performance of single channel reactors lays 
between plug flow and laminar reactors [12]. This type of design improves significantly the mixing, reaction and heat-transfer rates [13-15].

Compared to other designs, single channel designs show even flow distributions and higher flow velocities, which reduces the stagnant film adjacent to the channel walls and improves the heat-transfer rates [13-16]. High reaction rates are also observed in this designs which lead higher conversions. Despite the advantages, single channel designs impose a significant pressure drop penalty that may be a limitation for compact applications [14].

\section{Multi-channels reformer}

Reformers with parallel channels have been intensively reported in literature $[17,18,19]$. Based on parallel channels, several other designs can be obtained, such as wavy, pinhole and oblique-fin [14]. They are relatively easy to manufacture, show high conversions and low-pressure drop. However, parallel channels designs are more prone to uneven flow distributions. By adjusting the channels width [18] or by imposing a considerable pressure drop at the entrance of the channels the flow distribution can be optimized. In fixed bed reactors, depending on the specific design of the reactor, the pressure drop generated on the catalyst bed can be sufficient to obtain even flow distributions. Rebrov et al. [19] defined the guidelines to improve the heat distribution on parallel multi-channel reactors that includes adjusting the thickness of the channel walls and using a non-uniform coolant flow.

\section{Radial reformer}

The radial design is not very common for MSR applications despite presenting interesting features, such as large mean cross-sectional area and short flow travel distance compared to single channel reactors, resulting in low pressure drop. In a single channel reformer, the flow velocity increases due to the pressure difference between the inlet and the outlet and also due to an increase on the molar flow rate, according to the reaction stoichiometry (equation 1). In the radial design, however, the flow velocity decreases as it moves towards the outlet, when the reactor is fed from the center to the periphery, due to an increase of the cross-sectional area. For a diffusion-limited reaction, a large variation of surface velocity is detrimental for the conversion of the reactor [20,21].

In the present work, three cellular reformers with different designs (multi-channel, radial and tubular packed bed reactors) were manufactured and analyzed, either experimentally or by CFD in what concerns their performance for the MSR. 


\section{Experimental}

\subsection{MSR reactors}

The cellular reformers were designed to be sandwiched with HT-PEMFC in a stack arrangement. Heat and mass transport, pressure drop, flow-pattern and reactor volume were aspects taken into account since they affect the reformer performance [11]. The previous aspects are all important, but the reformer size is critical due to practical reasons, which depends directly on the catalyst activity.

Three stainless steel packed bed reformers were manufactured with different designs, namely multi-channel, radial and tubular. They were based on the best available literature information, though new features were introduced in order to improve their performance (Figure 1). Although stainless steel 316 is not as good as aluminum in terms of thermal conductivity, it presents better chemical stability towards methanol.

The multi-channel reformer (Figure 1a) was designed to match a $25 \mathrm{~cm}^{2} \mathrm{HT}$-PEMFC area, with outer dimensions of $95 \mathrm{~mm}$ x $95 \mathrm{~mm}$ x $10 \mathrm{~mm}$. The reformer has 21 channels with $51 \mathrm{~mm}$ of length and $2 \mathrm{~mm}$ of width. The channels depths gradually increase towards the central part of the cell, from $4 \mathrm{~mm}$ to $6 \mathrm{~mm}$. The inlet and outlet holes were drilled under the catalyst bed and act as distributors. They connect with the catalyst bed through a slit on the top. A stainless steel mesh (ca. 200 mesh) was used to cover the slits in order to avoid dragging the catalyst out from the bed. Two holes with different depths were made under the catalyst bed to insert thermocouples at different axial positions.

The radial reformer (Figure $1 \mathrm{~b}$ ) was also designed to match a $25 \mathrm{~cm}^{2} \mathrm{HT}$-PEMFC and the outer dimensions are $95 \mathrm{~mm}$ x $95 \mathrm{~mm}$ x $8 \mathrm{~mm}$. To hold the catalyst in place, a sintered ring was used, with inner diameter of $59 \mathrm{~mm}$, thickness of $2 \mathrm{~mm}$ and height of $5 \mathrm{~mm}$. The sintered ring creates also a small pressure drop which benefits the flow distribution. Next to the sintered ring a small channel collects the reformate stream and directs it to the outlet.

The tubular reformer was used as reference and it has $325 \mathrm{~mm}$ of length, $7 \mathrm{~mm}$ of internal diameter and $10 \mathrm{~mm}$ of external diameter.

The reactors performance was assessed using commercial catalyst G66 MR from Süd-Chemie $\left(\mathrm{CuO} / \mathrm{ZnO} / \mathrm{Al}_{2} \mathrm{O}_{3}\right)$. The experimental data was used to validate the $\mathrm{CFD}$ models. 


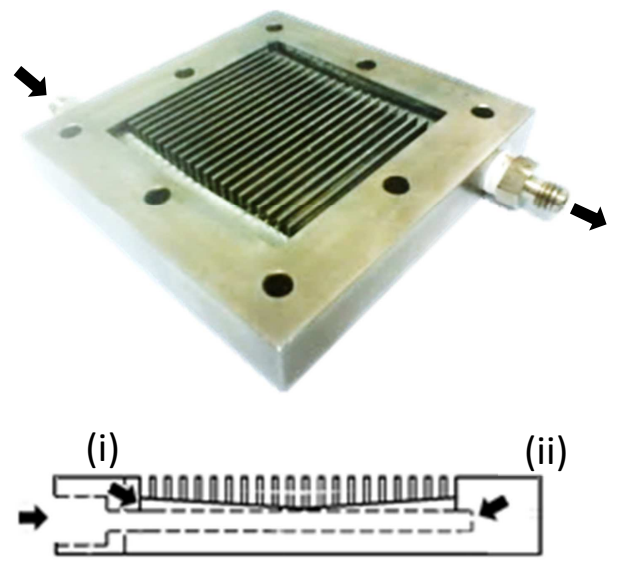

(a)

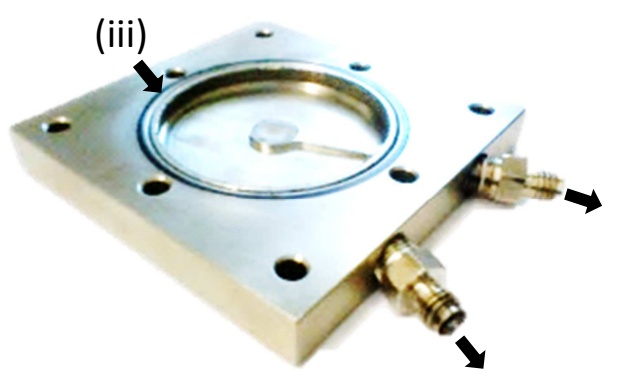

(b)

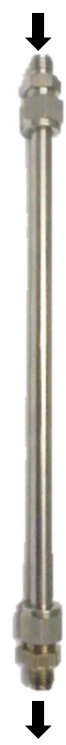

(c)

Figure 1 - Manufactured reactors: a) Multi-channel reformer, top and section view; b) Radial reformer; c) Tubular reformer. i) slit; ii) distributor; iii) metal sintered ring for feed distribution;

\subsection{Experimental procedure}

The reformers were filled with $15.5 \mathrm{~g}$ of commercial catalyst (G66MR), closed and placed inside an oven with controlled temperature. The catalyst was reduced in situ during 3 hours with $50 \mathrm{ml} \cdot \mathrm{min}^{-1}$ of hydrogen, at $443 \mathrm{~K}$. The reduction reaction rate was kept low in order to avoid any sintering of the catalyst. The reforming reaction was carried out between $453 \mathrm{~K}$ and $513 \mathrm{~K}$ and at space time values $\left(m_{\text {cat }} / F_{\text {MeOH }}\right)$ between $50 \mathrm{~kg} \cdot \mathrm{s} \cdot \mathrm{mol}^{-1}$ and $1500 \mathrm{~kg} \cdot \mathrm{s} \cdot \mathrm{mol}^{-1}$. The water/methanol mixture was pumped using an HPLC pump (LaPrep $\mathrm{P} 130)$. The value of the molar steam to carbon ratio (S/C) was 1.5 , since it is considered a good compromise to maximize the methanol conversion without wasting much energy in water evaporation [6].

The water/methanol mixture was evaporated using a serpentine placed inside the oven with forced air circulation. The phase transition of the water/methanol mixture creates strong flow fluctuations. In order to minimize that effect, the operating pressure was adjusted to 1.5 bar using a relief valve placed after the reformer.

The reformate stream was passed through a cold trap to remove the condensable components; the flow of the non-condensable species was measured using a mass flow meter (Bronkhorst); hydrogen and carbon dioxide concentration was determined by mass spectrometry (Pfeiffer OmniStartm) and CO using a specific analyzer (Signal Inst. 7000FM 
GFC). To determine the pressure drop in the reformers, the pressure was measured at the inlet using a nitrogen flow of $100 \mathrm{ml} \cdot \mathrm{min}^{-1}$ at $453 \mathrm{~K}$. The effect of the pressure drop on the methanol conversion was also assessed at different operating pressures ( 1 bar to 3 bar).

\section{CFD Modeling}

The experimental evaluation of reactors concerning heat profiles and flow distribution is a very difficult and time consuming process. CFD techniques are nonintrusive tools that provide a good agreement between numeric and experimental results. Therefore a CFD analysis was carried out using commercial software Fluent, from Ansys ${ }^{\mathrm{TM}}$. The reformers (Figure 1) were modelled using a three-dimension approach and validated with the data collected from the experimental runs.

\subsection{Mathematical model}

The model proposed in this study was based on assumptions as described next. The model was considered in steady-state. In the temperatures range considered, all the reaction species were in gas phase, behaving as ideal gases. In the operating conditions, the fluid flow was assumed laminar and Newtonian. The catalyst bed porosity was considered to be homogeneous, with uniform particles size and isotropic. No diffusion limitations in the catalyst were considered. Regarding the heat transfer in the reformer, both conduction and convection mechanisms were considered. Due to the good thermal conductivity of the SS316, no temperature gradients were assumed in the metal envelop of the reformers. The methanol steam reforming reaction was assumed as taking place only in the catalyst bed. The catalyst properties used in the simulations are given in Table 1.

Table 1 - Physical characteristics of Süd-Chemie G66MR catalyst [22].

\begin{tabular}{|l|l|}
\hline Density & $1.1 \mathrm{~g} \cdot \mathrm{cm}^{-3}$ \\
\hline Porosity & 0.38 \\
\hline Particle size & $100 \mu \mathrm{m}-250 \mu \mathrm{m}$ \\
\hline Thermal conductivity & $0.30 \mathrm{~W} \cdot \mathrm{m}^{-1} \cdot \mathrm{K}^{-1}$ \\
\hline
\end{tabular}

\section{Boundary conditions}

The boundary conditions considered for the reformer model are as follows:

- At the inlet, the flow velocity, gas composition and temperature were considered constant and equal to a specified value ; 
- At the outlet, the pressure was considered to be 1.5 bar, gradients of temperature and species mass fraction are equal to zero;

- At the wall, the temperature was considered constant and the flow obeys to the no slip condition.

In order to analyse the effect of the mesh on the numerical results, several runs were performed. The mesh considered in the simulations gives a methanol conversion with a maximum difference of $0.05 \%$ relatively to the value obtained using a mesh with the double of nodes. The meshes considered for the multichannel, radial and tubular models have a number of nodes of $5.9 \times 10^{5}, 2.9 \times 10^{5}$ and $2.1 \times 10^{5}$, respectively.

The mass, energy and momentum equations for the reaction species are described in the following:

\section{Continuity Equation}

$$
\nabla \rho \vec{u}=0
$$

Equation 4 is the mass conservation equation, where $\rho$ is the fluid density $\left(\mathrm{kg} \cdot \mathrm{m}^{-3}\right), \vec{u}$ is the fluid velocity vector $\left(\mathrm{m} \cdot \mathrm{s}^{-1}\right)$ and $\nabla$ is the gradient.

\section{Momentum Balance}

$$
\begin{aligned}
& \rho \vec{u} \nabla \vec{u}=-\nabla P+\nabla \tau+S, \quad \text { where } \tau=\mu\left(\nabla \vec{u}+\nabla \vec{u}^{T}-\frac{2}{3} \nabla \vec{u} I\right), \\
& S=-\left(\frac{\mu}{\alpha} \vec{u}+\frac{1}{2} \mathrm{C}_{2}|\vec{u}| \vec{u}\right), \quad \alpha=\frac{D_{\mathrm{p}}^{2}}{150} \frac{\varepsilon^{3}}{(1-\varepsilon)^{2}}, \quad C_{2}=\frac{3.5}{D_{p}} \frac{(1-\varepsilon)}{\varepsilon^{3}}
\end{aligned}
$$

Equation 5 is the conservation momentum equation and is known as the Navier-Stokes equation, in an inertial reference frame. The left member is the convective acceleration and represents the fluid particles acceleration with space. $\nabla P$ is the pressure $(\mathrm{Pa})$ gradient and is the isotropic part of Cauchy stress tensor; $\nabla \tau$ is the anisotropic part of the stress tensor and describes the viscous forces, where $\mu$ represents the viscosity $\left(\mathrm{kg} \cdot \mathrm{m}^{-1} \cdot \mathrm{s}^{-1}\right)$ and $I$ is the unit tensor or identity matrix; $S$ is the source term and represents the external body forces. In this model, the source term is the pressure gradient (drop) in a porous media and is composed by viscous losses (first term) and inertia losses (second term), where $D_{p}$ is particle diameter (m) and $\varepsilon$ is the media porosity. 


$$
\nabla \overrightarrow{\rho u} \omega_{i}=\nabla J_{i}+M_{i} v_{i} r_{M S R}, \quad J_{i}=\rho D_{i} \nabla \omega_{i}+D_{T, i} \frac{\nabla T}{T}
$$

To calculate the local mass fraction of the species $i, \omega_{i}$, it was used a convection-diffusion equation (equation 6). $J_{i}$ is the mass diffusion flux of the species $i\left(\mathrm{~kg} \cdot \mathrm{m}^{-2} \cdot \mathrm{s}^{-1}\right)$ and is composed by a mass diffusion term described by the Fick's law (being $D_{i}$ the mass diffusion coefficient) and a thermal diffusion term, known as Soret effect (being $D_{T, i}$ the thermal diffusion coefficient). The second term on the right side is the mass flux of species $i$ due to the chemical reaction, where $M_{i}$ is the molar mass of species $i\left(\mathrm{~kg} \cdot \mathrm{kmol}^{-1}\right), v_{i}$ is the stoichiometric coefficient of species $i$ in MSR reaction and $r_{M S R}$ is the reaction rate $\left(\mathrm{kmol} \cdot \mathrm{m}^{-3} \cdot \mathrm{s}^{-1}\right)$.

\section{Energy Balance}

$$
\begin{aligned}
& \nabla \vec{u} \rho H_{0}=\nabla\left(K_{e f f} \nabla T-\sum_{i} H_{i} J_{i, j}+\tau_{e f f} \vec{u}\right)-\nabla \vec{u} P+S_{H}, \\
& S_{H}=\sum_{i=1}^{N}\left(\Delta H_{k, 298}+\sum_{i} v_{i} \int_{298}^{T} C p_{i} d T\right)\left(r_{i}\right), H_{i}=\int_{T_{\text {ref }}}^{T} C p_{i} d T, H_{0}=\sum_{i}^{N_{c}} y_{i} H_{i}
\end{aligned}
$$

Equation 7 represents the conservation of energy. The left member is the total energy flux, where $H_{0}$ is the total enthalpy. In the right side, the first three terms are the energy flux by conduction, diffusive flux and by viscous forces, respectively. $K_{\text {eff }}$ is the effective thermal conductivity, which takes into account the thermal conductivity in the solid phases and gas phase $\left(\mathrm{W} \cdot \mathrm{m}^{-1} \cdot \mathrm{K}^{-1}\right)$ and $T$ is the temperature $(\mathrm{K})$. The fourth member is the pressure work. $S_{H}$ is the source term and represents the heat flux due to the chemical reaction, where $C_{p}$ is the specific heat capacity $\left(\mathrm{J} \cdot \mathrm{kg}^{-1} \cdot \mathrm{K}^{-1}\right)$

\section{Kinetic model}

In this work, a power law kinetic model was used, as presented in Eq. 8. These kinetic models are mechanistic derived, but they are simple and have been successfully used to fit experimental data in the literature [23-24].

The kinetic model used in this study only considers the MSR reaction; WGS and MD reactions were not considered due to their very low reaction rates at temperatures below $473 \mathrm{~K}$ [24]. This assumption is also supported by the very low CO concentrations measured in the reformate stream (Figure 4), which showed to be never higher than 
$0.15 \%$. The negative exponents on $\mathrm{H}_{2}$ and $\mathrm{CO}_{2}$ concentrations in equation 8 are related to the reversibility of the MSR reaction:

$$
-r=k_{0} e^{-\frac{E_{a}}{R T}} C_{\mathrm{CH}_{3} \mathrm{OH}}^{0.56} C_{\mathrm{H}_{2} \mathrm{O}}^{0.28} C_{\mathrm{H}_{2}}^{-0.07} C_{\mathrm{CO}_{2}}^{-0.09}
$$

where, $-r$ is the reaction rate of the methanol steam reforming reaction $\left(\mathrm{kg} \cdot \mathrm{m}^{-3} \cdot \mathrm{s}^{-1}\right), k_{0}$, is

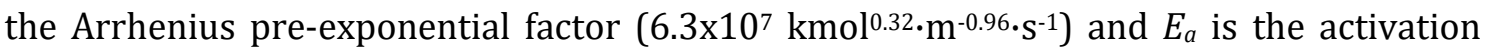
energy $\left(80 \times 10^{6} \mathrm{~J} \cdot \mathrm{kmol}^{-1}\right)$. The kinetic parameters were estimated based on the experimental results obtained with the tubular reactor. The parameters estimation was carried using the differential method by fitting a non-linear regression to the conversion vs. $m_{\text {саt }} / F_{\mathrm{MeOH}}$ experimental data and minimizing the sum of residual squares.

\section{Results and discussion}

\subsection{Model validation}

Figure 2 shows the experimental and simulated methanol conversion and hydrogen production over different space-time values at $453 \mathrm{~K}, 463 \mathrm{~K}$ and 473 for the three reformers. The simulation results using the kinetic model (equation 8) present a good agreement with the experimental data for the studied conditions, as shown in the parity plot (Figure 3). The reformers performance presents some differences concerning the attained methanol conversion, depending on the temperature and space time ratio values. Nevertheless, and excepting the radial reactor for the lowest temperature (Figure 2), full conversion may be reached for contact times above a threshold value (defined on section 4.2), which lowers with temperature increase, as expected due to higher catalyst activity. The radial reformer is clearly less efficient than the other two, except for the high contact time region (high space time ratio) and for the temperatures of $463 \mathrm{~K}$ and $473 \mathrm{~K}$. The tubular and multi-channel reactors perform quite similar, with a small difference in the intermediate contact time region for the lowest temperature $(453 \mathrm{~K})$, which progressively moves for low contact time values as the temperature increases. The reasons for this behavior are discussed below (section 4.4).

The low reaction rate of the catalyst at $453 \mathrm{~K}$ demands more catalyst to achieve the full conversion, which is problematic in compact systems. 


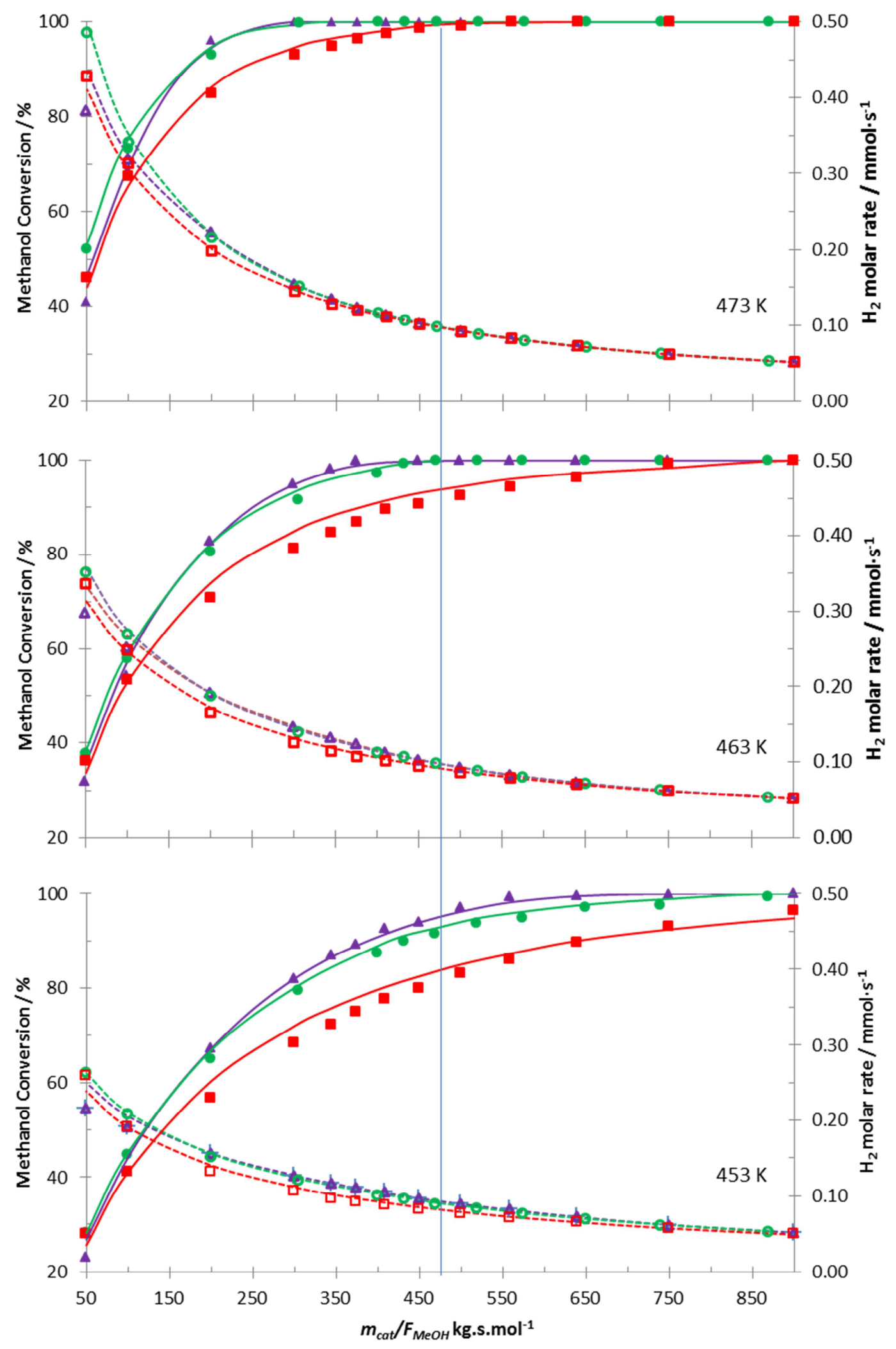

Figure 2 - Experimental (symbols) and simulated (lines) results for the methanol conversion (left axis) and produced hydrogen molar flow rate (right axis) versus the space time ratio at different temperatures; Tubular reactor( purple); Multi-channel reactor (green); Radial reactor(red). 


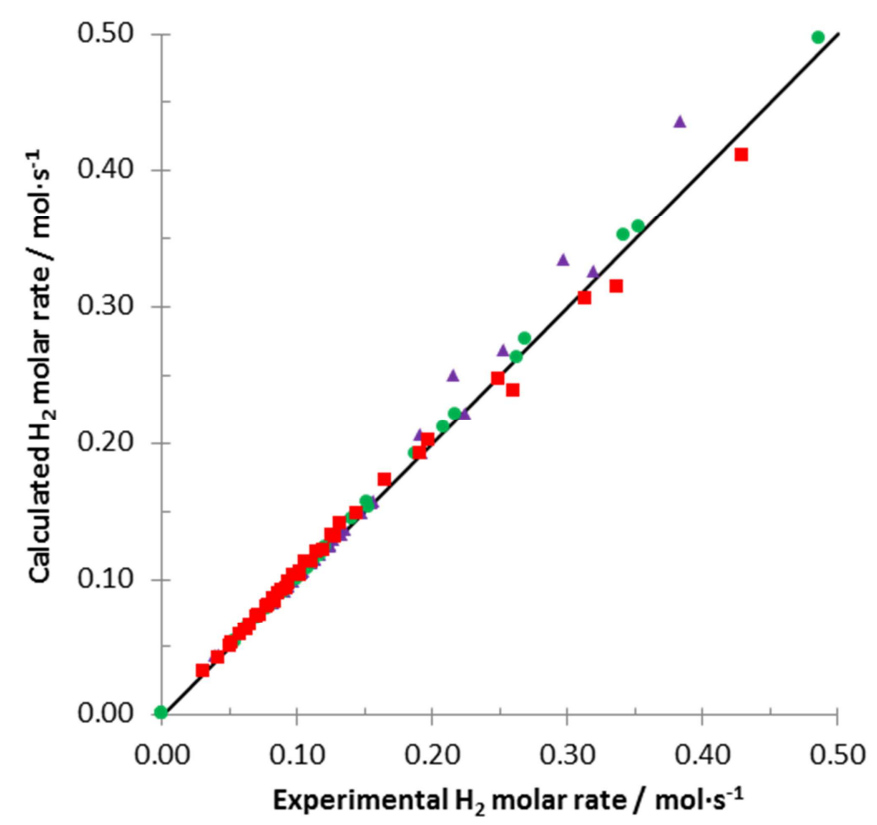

Figure 3 -Parity plots of the experimental and calculated hydrogen molar rate. Tubular reactor (purple); Multi-channel reactor (green); Radial reactor (red).

\subsection{MSR/PEMFC integration}

As previously mentioned, the goal of this work is the thermal integration of a MSR-C with a fuel cell in a stack arrangement. HT-PEMFCs with PBI membranes operate at a maximum temperature of $473 \mathrm{~K}$, since higher temperatures compromise the stability of the membrane [25]. However, other membranes based on pyridine aromatic polyethers promise to be more stable at higher temperatures [26].

A $25 \mathrm{~cm}^{2}$ HT-PEMFC, operating at $0.6 \mathrm{~A} \cdot \mathrm{cm}^{-2}$, requires ca. $9.34 \times 10^{-5} \mathrm{~mol} \cdot \mathrm{s}^{-1}$ of hydrogen (assuming that ca. $20 \%$ of hydrogen is vented). Though the experimental assessment of the HT-PEMFC tolerance to methanol bleeding was not performed, it has been assumed a minimum methanol conversion of $95 \%$, thus requiring a minimum methanol flow rate of $3.3 \times 10^{-5} \mathrm{~mol} \cdot \mathrm{s}^{-1}$. Taking into account the catalyst mass placed in the reactors $(15.5 \mathrm{~g})$, the maximum $m_{\text {cat }} / F_{\mathrm{MeOH}}$ is $473 \mathrm{~kg} \cdot \mathrm{s} \cdot \mathrm{mol}^{-1}$. At the same operating condition using a reformer of $320 \mathrm{~cm}^{3}$ filled with $149 \mathrm{~g}$ of catalyst pellets of $\mathrm{CuO} / \mathrm{ZnO} / \mathrm{Al}_{2} \mathrm{O}_{3}$, Pan et al. [6] reported nearly $100 \%$ of methanol conversion for $m_{\text {cat }} / F_{\text {MeOH }}$ $>1200 \mathrm{~kg} \cdot \mathrm{s} \cdot \mathrm{mol}^{-1}$. Better results were achieved in this work, even though none of the previous reformers produce the required hydrogen flow rate $\left(9.34 \times 10^{-5} \mathrm{~mol} \cdot \mathrm{s}^{-1}\right)$ at $453 \mathrm{~K}$. The multi-channel reformer reached $95 \%$ of methanol conversion at $m_{\text {cat }} / F_{\text {MeOH }}$ of 
$600 \mathrm{~kg} \cdot \mathrm{s} \cdot \mathrm{mol}^{-1}$ and $453 \mathrm{~K}$, while the radial reformer reached the same value only at spacetime values higher than $1000 \mathrm{~kg} \cdot \mathrm{s} \cdot \mathrm{mol}^{-1}$.

To produce the required hydrogen flow rate $\left(9.34 \times 10^{-5} \mathrm{~mol} \cdot \mathrm{s}^{-1}\right)$ with $95 \%$ of methanol conversion, it is necessary to operate at temperatures higher than $453 \mathrm{~K}$. At $463 \mathrm{~K}$, the multichannel and the tubular reformers satisfied the previous conditions. The radial reformer at that temperature still was under performing. All these reformers were characterized using fresh catalyst; typically catalysts deactivate $c a .20 \%$ after few hours of time on stream [8]. Despite this fact, the tubular and multichannel reformers still were capable to produce enough hydrogen to feed a FC.

Large reformers, such as the one used by Pan et al. [6], exhibit heat transfer limitations. Additionally, large catalyst particles, in the range of in the range of few millimeters, were used to minimize the pressure drop. As a consequence, the overall reaction rate becomes limited by the mass transfer of reactants between the bulk fluid and catalytic surface. Thus, it is important to achieve a balance between particle size and pressure drop. Catalyst powders with particle size between $100 \mu \mathrm{m}$ and $250 \mu \mathrm{m}$ were used in this work. The pressure drop in the reformers was assessed using a nitrogen flow of $100 \mathrm{ml} \cdot \mathrm{min}^{-1}$ at $453 \mathrm{~K}$. The highest pressure-drop value was obtained for the tubular reformer, $c a$. 170 mbar, while the multi-channel and radial reformers showed less than 10 mbar of pressure drop. The pressure drop and operating pressure showed a small influence on the methanol conversion, decreasing less than $5 \%$ in all reformers when the pressure changes from 1 to 3 bar at $453 \mathrm{~K}$

According to the literature, carbon monoxide concentration lower than $20000 \mathrm{ppm}$ - $30000 \mathrm{ppm}$ [6] does not affect significantly the HT-PEMFCs performance. The experimental carbon monoxide concentration in the reformate stream as a function of the space-time, at $453 \mathrm{~K}$ and $473 \mathrm{~K}$ and for the three reactors is presented in Figure 4.

The results show that the $\mathrm{CO}$ concentration at $453 \mathrm{~K}$ increases from $300 \mathrm{ppm}$ to $1000 \mathrm{ppm}$ for the space-time range analyzed. At $473 \mathrm{~K}$, the CO concentrations increases from $1000 \mathrm{ppm}$ to $1600 \mathrm{ppm}$, for the same space-time range. This way, the reformate stream does not require further purification to feed a HT-PEMFC. At temperatures lower than $573 \mathrm{~K}$ the methanol decomposition reaction (Eq. 3) has very low conversion being the CO almost exclusively produced from the reverse water gas shift reaction [9]. As a result, the CO concentration increases with the partial pressure of the MSR reaction products $\left(\mathrm{H}_{2}\right.$ and $\left.\mathrm{CO}_{2}\right)$. As shown in Figure 4, the multi-channel reactor produces similar concentrations of $\mathrm{CO}$ as the tubular and higher than the radial reformer, mainly due to heat profiles as it will be discussed later. 


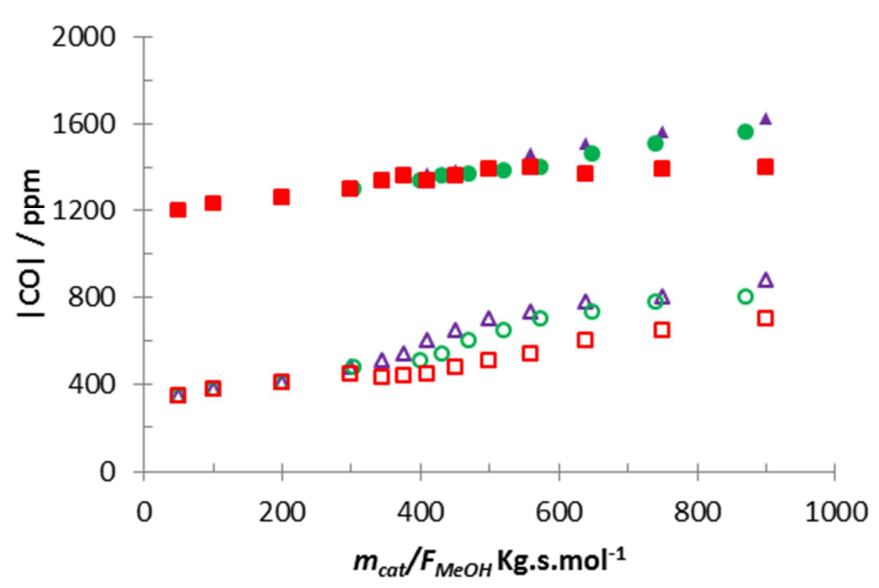

Figure 4 - $\mathrm{CO}$ concentration versus the space time ratio, at $453 \mathrm{~K}$ (empty symbols) and $473 \mathrm{~K}$ (filled symbols) and at 1.5 bar; - $\Delta$ - Tubular reactor; - • - Multi-channel reactor; -

- Radial reactor.

\subsection{Flow distribution}

To show an optimised performance, the reformer design must provide a good flow distribution, assuring that all the available catalyst is fully used. However, the catalyst full exploitation also depends on the size and shape of the respective particles, for a given set of operating conditions. Catalyst powders are composed of very small irregular particles, which benefit the mass diffusion into the catalyst particle surface, but have a detrimental effect on pressure drop and flow distribution [27]. To minimize these negative aspects the size distribution of the catalyst powder was as narrow as feasible.

In the following, the flow distribution in the different reactors will be analyzed in more detail.

Flow velocity profiles in the multi-channel reactor

Multi-channel designs characteristically exhibit small-pressure drop and the flow distribution in the different channels is governed by the Reynolds number calculated at the inlet conditions [14]. To optimize the flow distribution in the multichannel reformer, an inlet and outlet distributor was used in the present study located underneath the catalyst bed as described previously. The porous media (catalyst bed) imposes a momentum resistance (sink) due to viscous and inertia losses (equation 5), which contributes for a homogenization in the flow distribution.

Figure 5 shows the simulated average flow velocity on the channels, at the middle axial position, for the multi-channel reformer. 


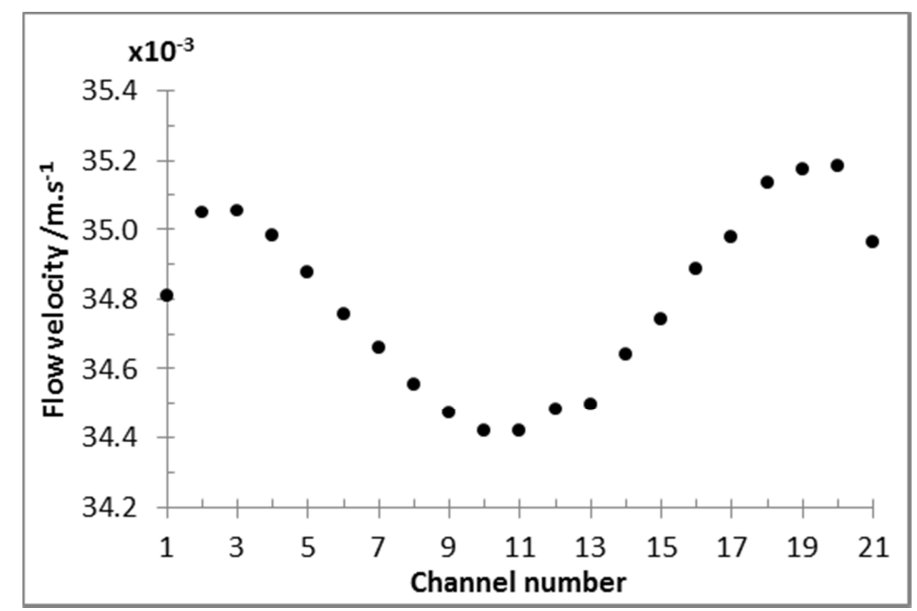

Figure 5 - Flow velocity determined in the middle of the channels for multi-channel reformer with $m_{\text {cat }} / F_{\mathrm{MeOH}}=300 \mathrm{~kg} \cdot \mathrm{mol} \cdot \mathrm{s}^{-1}$, wall temperature $453 \mathrm{~K}, P_{\text {out }}=1 \mathrm{bar}$ and $S / C=1.5$.

The coefficient of variation of the flow velocity in the channels was calculated to assess the goodness of the flow distribution. The coefficient of variation was in the range $0.6 \%$ to $0.8 \%$ for a space time ratio from $900 \mathrm{~kg} \cdot \mathrm{mol} \cdot \mathrm{s}^{-1}$ to $50 \mathrm{~kg} \cdot \mathrm{mol} \cdot \mathrm{s}^{-1}$, respectively. The results obtained for the flow velocity distribution are similar with those obtained by Jang et al. [18] for a multichannel reformer. These authors improved the flow velocity distribution in a multichannel reformer optimising the width of the channels.

Although the CV values are very small, slightly higher flow velocities were observed in the outer channels relatively to the inner channels. In the development of the multichannel reactor a larger quantity of catalyst was considered in the middle of the bed, where the temperature of the stack (MSR/HT-PEMFC) is higher. Therefore, the channels depth was increased from the outer to the inner channels leading to this difference in the flow velocity among the channels. This small difference in flow velocity among channels should represent a minor penalty for the hydrogen production.

Figure 6 shows the simulated flow distribution of the multi-channel reformer. In the channels region is observed a quasi plug flow behaviour that benefits the performance. However, dead zones are observed in the distributors near the entrance and exit walls, due to the central position of inlet and outlet distributor slit. As a result, the catalyst in these regions is poorly used, which has a negative effect in the hydrogen production. This negative effect, explains the difference in the methanol conversion observed in Figure 2 between tubular and multichannel reformers at temperature of $453 \mathrm{~K}$. These dead zones however were expected, as long as they do not affect significantly the flow distribution in 
the channels and in order to use all the available volume of the reformer, they were considered acceptable.

To improve this reactor performance the inner and outlet distributor should be thinner and the slits should be located not in the middle of the distributors but by the reactor walls. This would improve the flow distribution and consequently the methanol conversion.

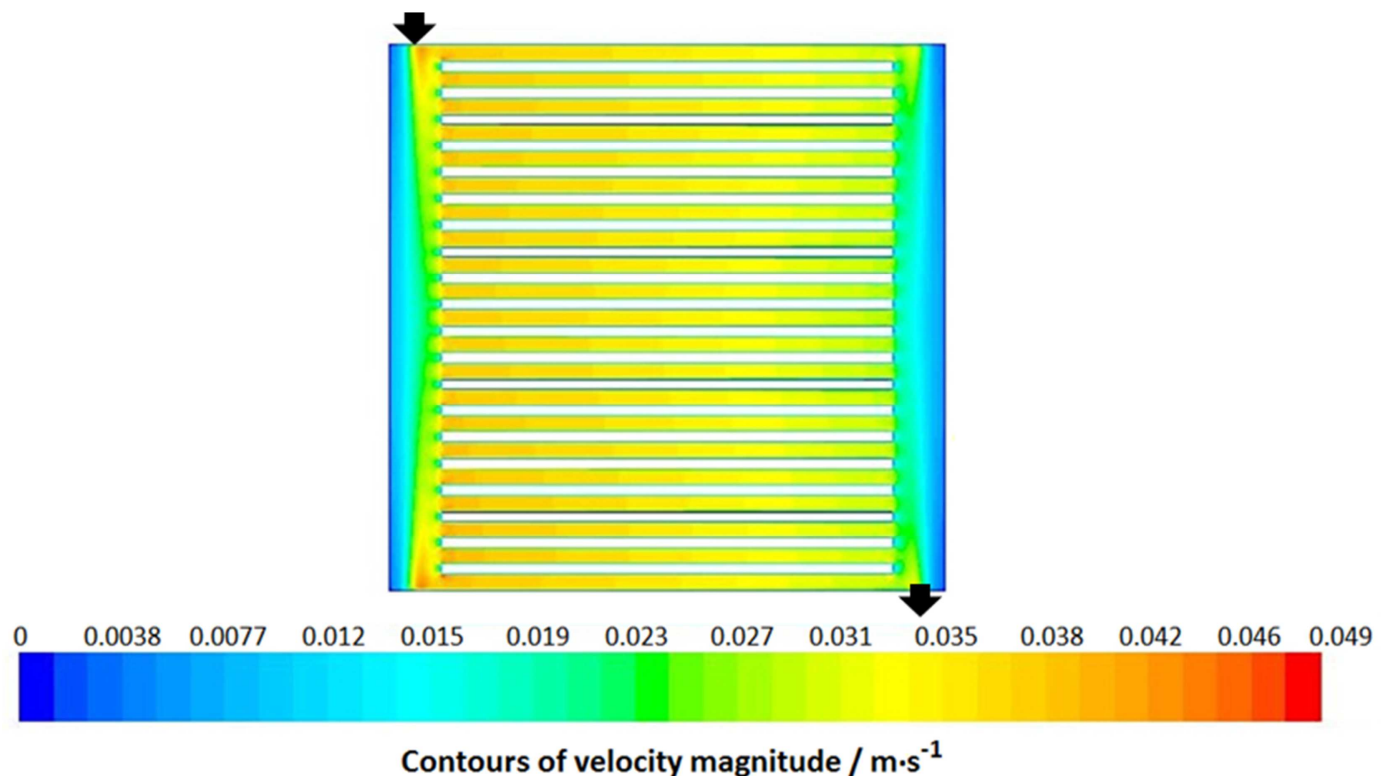

Figure 6 - Flow velocity contours of multi-channel reformer with $m_{\text {cat }} / F_{\text {MeOH }}=300$ $\mathrm{kg} \cdot \mathrm{mol} \cdot \mathrm{s}^{-1}$, wall temperature $453 \mathrm{~K}, P_{\text {out }}=1$ bar and $S / C=1.5$.

The tubular reformer behaved as a plug flow reactor with no dead zones, as expected (not shown). The plug flow behaviour and the absence of dead zones on the tubular reformer explain the higher methanol conversion at $453 \mathrm{~K}$ when compared to the multi-channel and radial reformer.

\section{Flow velocity profiles in the radial reactor}

The velocity profile obtained for the radial reformer (Figure $7 \mathrm{~b}$ ) agrees with the results reported by Pattekar et al. [21] where low and steady flow velocities are observed. However, the high performances presented by Pattekar et al. for this design were not observed in the present work.

The low performance of the radial reformer can be justified by the flow velocity profile; this reformer presents a laminar flow with a very interesting behaviour, with large regions near the upper and lower walls with very low flow velocity, as shown in Figure $7 \mathrm{~b}$. 
This behaviour differs from the multi-channel reformer, where the reactor design creates stagnant regions and channels with different flow velocities.

Typically, in laminar flows the fluid profile becomes fully developed at a short distance from the leading edge. A fluid profile is considered fully developed, when the boundary layer thickness (i.e. the layer in which the velocity grows from zero at the wall no slip condition - to $99 \%$ of the maximum velocity in the middle of the channel) reaches a constant value. However, when the radial reformer is fed through the centre, the flow velocity decreases and depends on the balance between the increase of the cross-section area (velocity decrease), the pressure drop (velocity increase) and the total moles number due to the reaction stoichiometry (velocity increase), as described in Equation 1. As a result, the flow never becomes fully developed, since the boundary layer increases as the fluid velocity decreases. The thickness of the boundary layer is related to the inefficiency on the catalyst usage in this reactor.

a)
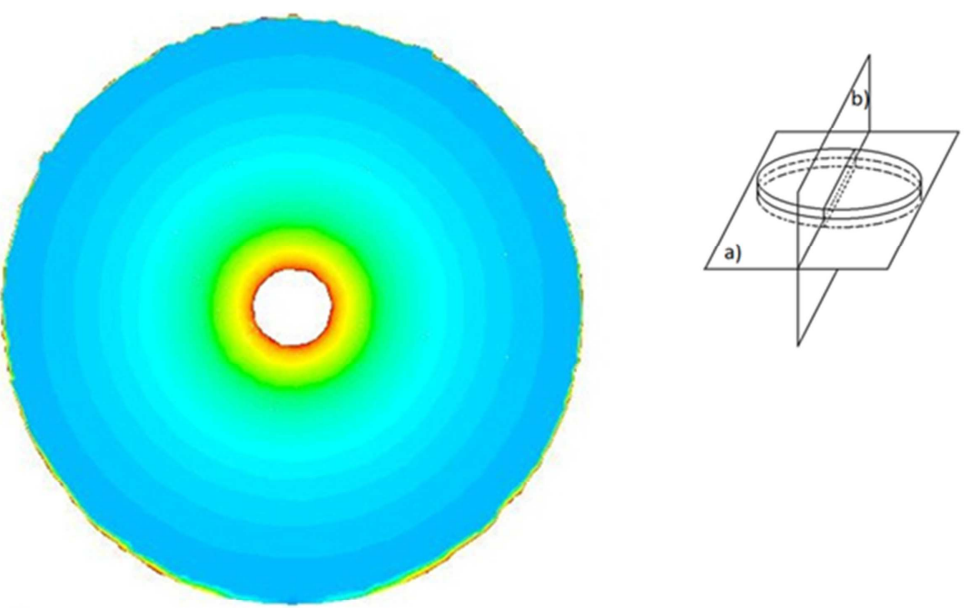

b)

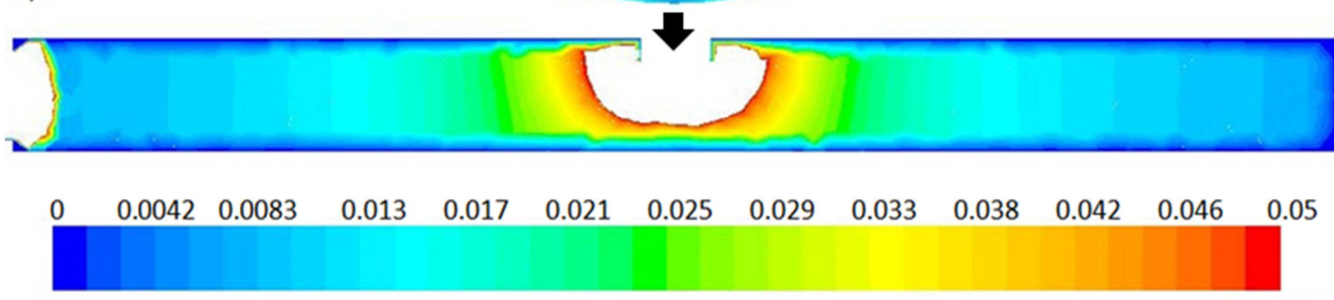

Contours of velocity magnitude $/ \mathrm{m} \cdot \mathrm{s}^{-1}$

Figure 7 - Flow velocity contours of radial reformer with $m_{\text {cat }} / F_{\text {MeOH }}=300 \mathrm{~kg} \cdot \mathrm{mol} \cdot \mathrm{s}^{-1}$, wall temperature $453 \mathrm{~K}, P_{\text {out }}=1$ bar and $S / C=1.5$ : a) radial section view (half-height); b) front section view. Velocities higher than $0.05 \mathrm{~m} \cdot \mathrm{s}^{-1}$ have been removed for a better illustration of the stagnate regions.

For a diffusion-limited or close to diffusion-limited reaction, the low flow velocity can benefit the reaction conversion. However, if very small catalyst particles are used, the 
reaction is rate limited, so the velocity effect on the methanol conversion should be minor. On the other hand, very low flow velocities create stagnated regions near to the wall and as a result the catalyst is poorly used, as previously mentioned.

Despite the low performance observed towards the methanol conversion, the radial reformer, due to the short flow travel distance of the fluid, presents the lowest pressure drop among the three reformers. This design can be an interesting option when the pumping power is a limitation. Even though, by reducing the height of the catalyst bed, higher flow velocities are achieved reducing the boundary layer and enhancing the hydrogen production.

\subsection{Heat transfer}

The slow reaction kinetics at $453 \mathrm{~K}$ demands high space time values to achieve $>95 \%$ of methanol conversion. On the other hand, the low flow velocity increases the thickness of the stagnated gas film on the reactor walls leading to a high heat transfer resistance [28]. The thermal conductivity is also affected by the void fraction, larger near the wall than in the bulk, limiting the number of contact points between the catalyst particles and the reactor wall. In the following, the temperature profiles for the different reactors are presented and discussed.

\section{Temperature profiles in the tubular reactor}

The temperature contours for the tubular reformer in the MSR reaction, at a wall temperature of $453 \mathrm{~K}$ and a space time of $300 \mathrm{~kg} \cdot \mathrm{s} \cdot \mathrm{mol}^{-1}$, is shown in Figure 8 . As it can be observed, there is a temperature sink of $7 \mathrm{~K}$ at the entrance of the reactor. This temperature drop indicates the existence of heat transfer limitations in this region of the reformer. The reasons for that are related with the endothermic nature of the reaction, the low thermal conductivity of the catalyst and the maximum reaction rate value in the inlet region.

Any drop in the temperature leads to a decrease of the conversion. Thus, it is of high importance to minimize as possible any temperature decrease. The heat demand in the reformer is not uniform, being higher close to the entrance where the reforming reaction is faster. However, it only reports to the initial stage of the reaction. To evaluate the limitations on the heat transfer the average temperature of the reformer was considered, since it provides an overall evaluation of the reactor. For temperature of $453 \mathrm{~K}$ and a space time of $300 \mathrm{~kg} \cdot \mathrm{s} \cdot \mathrm{mol}^{-1}$, the average temperature of the reformer was $451.5 \mathrm{~K}$, which does not significantly influence the methanol conversion, shown in Figure 9. As the reaction 
rate increases with the operating temperature, the heat transfer limitations become more important (e.g. at $473 \mathrm{~K}$ and for full methanol conversion, the temperature sink is $12.5 \mathrm{~K}$ and the average temperature is $470 \mathrm{~K}$, data not shown). Therefore, to minimize the heat transfer limitations at higher operating temperatures the tube diameters must be reduced.

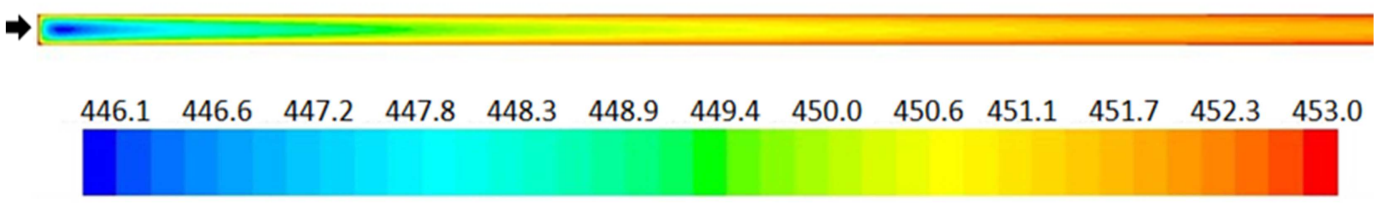

\section{Contours of static temperature / $\mathrm{K}$}

Figure 8 - Temperature contours for tubular reformer in the MSR reaction, with $m_{\text {cat }} / F_{\text {MeOH }}=300 \mathrm{~kg} \cdot \mathrm{mol} \cdot \mathrm{s}^{-1}$, wall temperature $453 \mathrm{~K}, P_{\text {out }}=1$ bar and $S / C=1.5$.

For the same reaction volume, smaller diameters correspond to longer lengths, which minimize the temperature sink, enhance the methanol conversion, but originate higher pressure drops. Karim et al. [23] estimated that the smallest diameter required for a packed bed to achieve near isothermal operation was $300 \mu \mathrm{m}$ at $503 \mathrm{~K}$. The benefit of operating at isothermal conditions must be evaluated. In order to analyse this benefit, different simulations were performed to compare the non-isothermal with the isothermal conditions (isothermal conditions were attained by increasing the catalyst thermal conductivity), which results are presented in Figure 9. At $453 \mathrm{~K}$ the benefit of having isothermal conditions showed to be small; for a space time of $300 \mathrm{~kg} \cdot \mathrm{s} \cdot \mathrm{mol}^{-1}$ the methanol conversion is $84.1 \%$ while at non-isothermal is $82.0 \%$. However, higher operating temperatures revealed the heat transfer limitations of this reformer, and at $473 \mathrm{~K}$ and for a space time of $150 \mathrm{~kg} \cdot \mathrm{s} \cdot \mathrm{mol}^{-1}$ the methanol conversion is $90.0 \%$ while for non-isothermal conditions is $85.9 \%$. From these results one can concluded that the diameter of the tubular reformer is acceptable to operate at $453 \mathrm{~K}$, but for higher temperatures smaller diameters are required. 


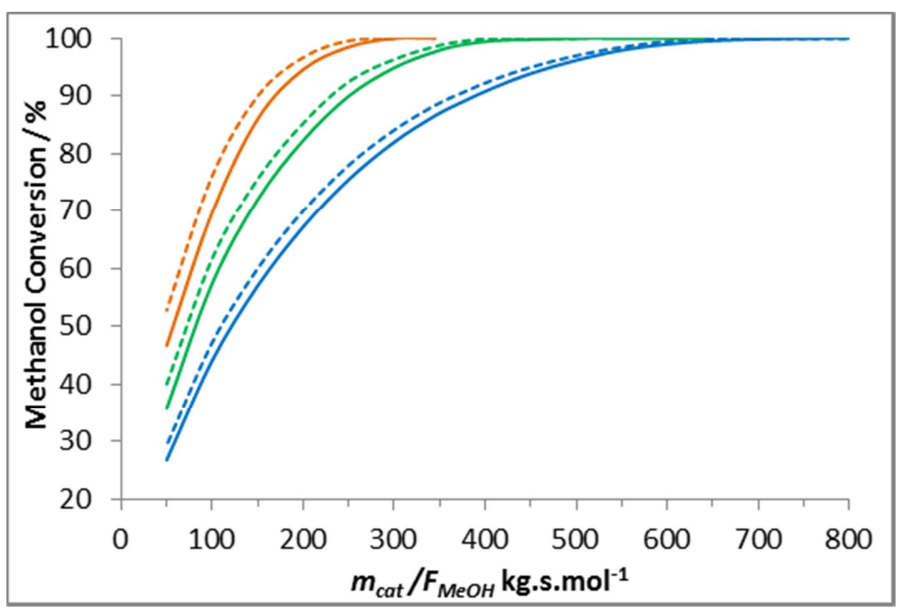

Figure 9 - Methanol conversion for plug-flow reactor at isothermal conditions (dash line) and tubular reformer at non-isothermal conditions (full line), with wall temperature of $453 \mathrm{~K}\left(\right.$ blue), $563 \mathrm{~K}$ (green) and $473 \mathrm{~K}$ (brown), $P_{\text {out }}=1$ bar and $S / C=1.5$.

\section{Temperature profiles in the multi-channel reactor}

The temperature contours for the multi-channel reformer in the MSR reaction, at wall temperature of $453 \mathrm{~K}$ and space time of $300 \mathrm{~kg} \cdot \mathrm{s} \cdot \mathrm{mol}^{-1}$, are plotted in Figure 10 . The temperature sink is $4 \mathrm{~K}$, lower than the obtained for the tubular reformer. Moreover, the reformer operates almost at isothermal conditions in the region of the channels. As a result the reformer average temperature was $452.5 \mathrm{~K}$, indicating minor heat transfer limitations. Even at $473 \mathrm{~K}$ the average temperature is $472.1 \mathrm{~K}$ with a maximum temperature sink of $7.4 \mathrm{~K}$ (not shown). Operating the multichannel reformer at $473 \mathrm{~K}$ with isothermal condition and space time of $150 \mathrm{~kg} \cdot \mathrm{s} \cdot \mathrm{mol}^{-1}$ (CDF results) shows $\mathrm{ca} .1$ percentage point difference on the methanol conversion compared to non-isothermal conditions. This shows that the major limitation of the multichannel reformer is not related to heat transfer limitations but with the flow distribution.

As the reaction rate increases with the temperature, it emphasizes the heat transfer limitations in the reformers and it gains significant influence on the methanol conversion. The inversion on the performance between multichannel and tubular reformer (Figure 2) as the temperature increases, especially at low space time values, is related to the higher efficiency on the heat transfer of the multi-channel reformer at higher temperatures. 


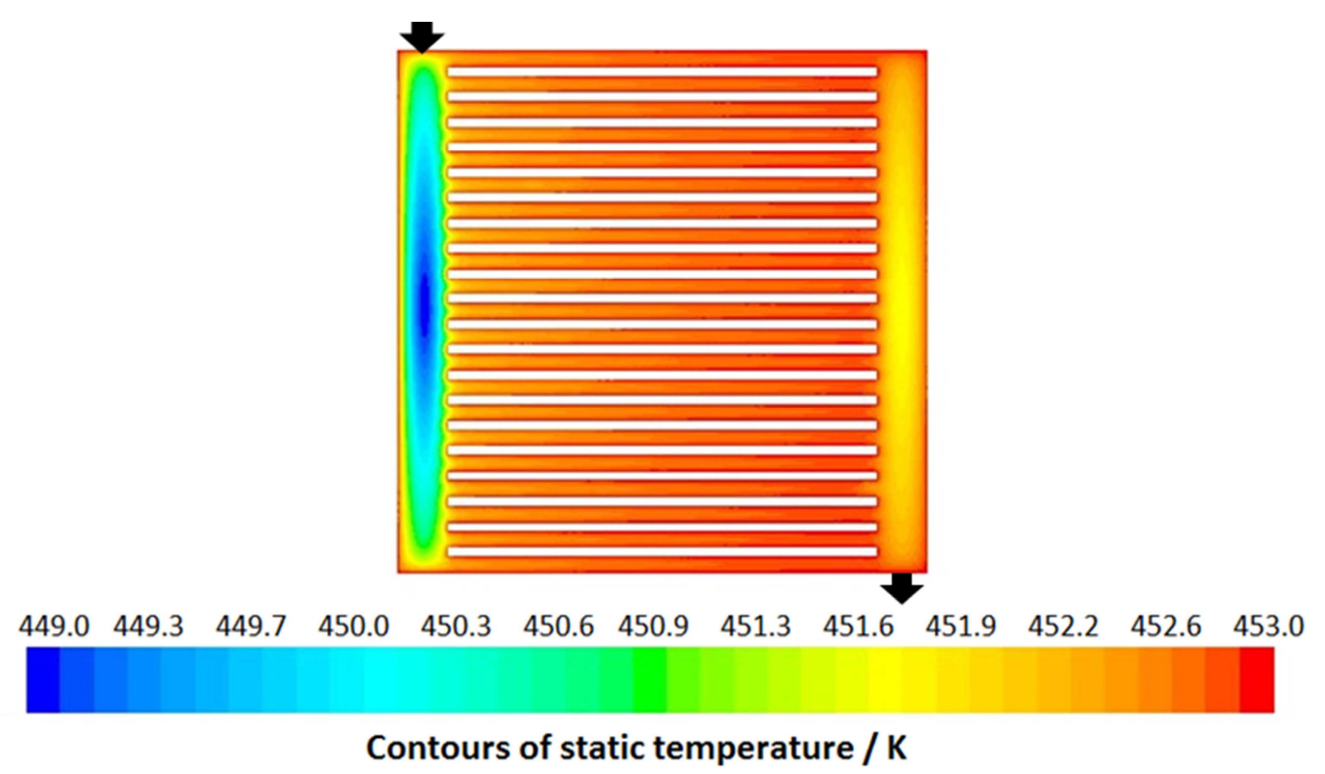

Figure 10 - Temperature contours for multi-channel reformer in the MSR reaction, with $m_{\text {cat }} / F_{\text {MeOH }}=300 \mathrm{~kg} \cdot \mathrm{mol} \cdot \mathrm{s}^{-1}$, wall temperature $453 \mathrm{~K}, P_{\text {out }}=1$ bar and $S / C=1.5$.

\section{Radial - temperature profiles}

The radial reformer presents important limitations regarding heat transfer as shown in Figure 11. As previously mentioned low flow velocities have detrimental effect on heat transfer by convection and the small metallic surface area in the radial reformer reduces the heat transfer wall/catalyst particle by conduction. Although the temperature sink is $5 \mathrm{~K}$ lower than in the tubular at $453 \mathrm{~K}$ with $m_{\text {cat }} / F_{\mathrm{MeOH}}$ of $300 \mathrm{~kg} \cdot \mathrm{s} \cdot \mathrm{mol}^{-1}$, the radial reformer presents an average temperature of $451.3 \mathrm{~K}$. The highest flow velocity was observed in the middle of the reformer, where the temperature was lower than $450 \mathrm{~K}$ (Figure 11), pointing toward the low conversions observed in this reformer. This design presents limitations regarding the heat transfer, which could be minimized by reducing the height of the catalyst bed. The insertion of metallic fins in an axial position would also allow increasing the heat transport to the catalyst bed improving the methanol conversion but reduces the loaded catalyst. 


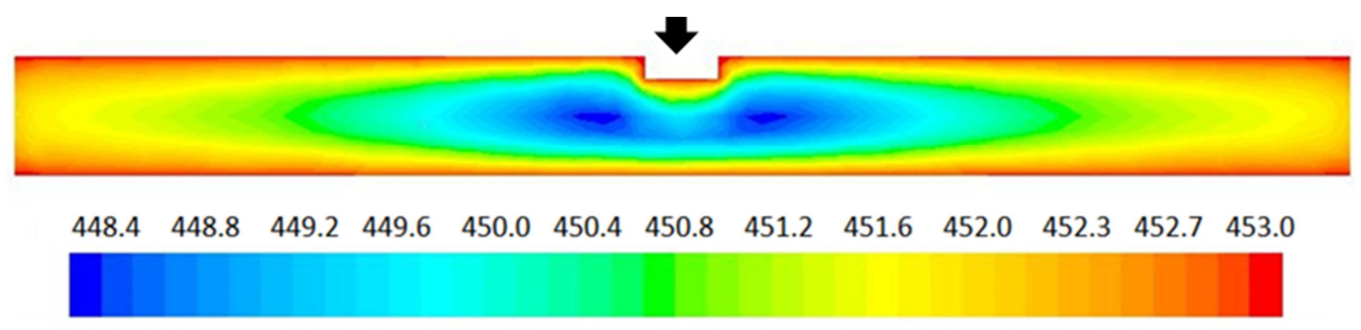

Contours of static temperature / $\mathrm{K}$

Figure 11- Temperature contours for radial reformer during MSR reaction, with $m_{\text {cat }} / F_{M e O H}=300 \mathrm{~kg} \cdot \mathrm{mol} \cdot \mathrm{s}^{-1}$, wall temperature $453 \mathrm{~K}, P_{\text {out }}=1$ bar and $S / C=1.5$.

\section{Conclusions}

Three different methanol reformer designs for thermal integration with a HTPEMFC were thoroughly studied experimentally and by CFD simulation. The results showed that the multi-channel design is the best solution for the thermal integration, with high methanol conversion and low pressure drop. The narrow channels and the high metallic surface area in the multichannel provided the lowest temperature sink among the studied reformers due to an efficient heat transfer from the wall to the bulk. The multichannel showed a good flow distribution with a coefficient of variation in flow velocity between channels in the range of $0.6 \%$ to $0.8 \%$.

Severe heat transfer limitations were observer in the radial reformer due to low flow velocities and small metallic surface area. The low flow velocity in the bed of the radial reformer had a negative effect on the catalyst usage reducing the methanol conversion. To obtain isothermal condition the tubular reformer diameter or the multichannel width must be reduced, but at low temperatures, $c a .453 \mathrm{~K}$, it presents small benefit, due to the low reaction rate.

The low activity of the MSR catalysts, at $453 \mathrm{~K}$ is still an issue to be solved. At higher temperatures, $c a .463 \mathrm{~K}$, the multichannel reformer can produce enough hydrogen to directly feed a HT-PEMFC with low CO content. The thermal integration of MSR/HTPEMFC in a stack arrangement is currently under investigation. 


\section{Acknowledgments}

The research leading to these results has received funding from the European Union's Seventh Framework Programme (FP/2007-2013) for the Fuel Cells and Hydrogen Joint Technology Initiative under grant agreement $n^{\circ}$ [303476]. Paulo Ribeirinha also wishes to thank FCT- Foundation for Science and technology for Research grant with reference "New Fuel Cell system using high efficient composite palladium membranes" PTDC/EQUEQU/104217/2008 and for the PhD fellowship, PD/BD/52621/2014. M. Boaventura is grateful to the Portuguese Foundation for Science and Technology (FCT) for her post-doc grant (reference SFRH/BPD/80599/2011).

\section{References}

[1]P. Atkins and J. De Palma, Atkin's Physical Chemistry $8^{\text {th }}$ ed. W. H. Freeman and Company, New York (2006).

[2] [access date December 2013], http://www.ultracellpower.com/sp.php?rmfc

[3] T. Huck, P. Engelhardt, K. Lucka, Highly integrated micro fuel cell system based on a methanol steam reformer and a HT PEM fuel cell. 15th Europeam Fuel Cell Forum. Lucern, Switzerland (2011).

[4] S. Andreasen, S. Kær, S. Sahlin, Control and experimental characterization of a methanol reformer for a 350W high temperature polymer electrolyte membrane fuel cell system, International Journal of Hydrogen Energy 38 (2013) 1676-84.

[5] Qi A., Peppley B., Karan k., Integrated fuel processors for fuel cell application: A review, Fuel Processing Technology 88 (2007) 3-22.

[6] C. Pan, R. He, Q. Li, J. Jensen, N. Bjerrum, H. Hjulmand, Integration of high temperature PEM fuel cells with a methanol reformer, J. Power Sources, 145 (2005) 392-398.

[7] G. Avgouropoulos, T. Ioannides, J. Kallitsis, S. Neophytides, Development of an internal reforming alcohol fuel cell: Concept, challenges and opportunities, Chem. Eng. J., 176 (2011) 95-101.

[8] A. Iulianelli, P. Ribeirinha, A. Mendes, A. Basile, Methanol steam reforming for hydrogen generation via conventional and membrane reactors: A review, Renewable and Sustainable Energy Reviews 29 (2014) 355-368. 
[9] G. Avgouropoulos, S. Neophytides, Performance of internal reforming methanol fuel cell under various methanol/water concentrations, Journal Applied Electrochemistry, 42 (2012) 719-726.

[10] K. Yu, W. Tong, A. West, K. Cheung, T. Li, George Smith, Y. Guo, S. Tsang, Non-syngas direct steam reforming of methanol do hydrogen and carbon dioxide at low temperature, Nature Communications, 2 (2012), 1230-1236.

[11] V. Hessel, S. Hardt, H. Lowe, Chemical Micro Processing Engeneering, Wiley-VCH (2004).

[12] S. Agrawal, K. Nigam, Modelling of a coiled tubular chemical reactor, Chemical Engineering Journal, 84 (2001) 437-444.

[13] A. P. Sasmito, J. C. Kurnia, A. S. Mujumdar, Numerical Evaluation of Transport Phenomena in a T-junction Microreactor with Coils of Different Configurations, Industrial \& Engineering Chemistry Research, 51 (2012)1970-1980.

[14] H. An, A. Angli, B. Agus, P. Sasmito, C. Jundika, A. Kurnia, V. Sachin, Jangam, S. Arun, Mujumdar, Computational fluid dynamics (CFD) analysis of micro-reactor performance: Effect of various configurations, Chemical Engineering Science, 75 (2012) 85-95.

[15] C. Hsueh, H. Chu, W. Yan, G. Leu, J. Tsai, Three dimensional analysis of a plate methanol steam micro reformer and a methanol catalytic combustor with different flow channel designs, International Journal of Hydrogen Energy, 36 (2011) 13575-13586.

[16] F. Mehri, M. Taghizadeh, Performance assessment of a spiral methanol to hydrogen fuel processor for fuel cell applications, Journal of Natural Gas, 21 (2012) 526-533.

[17] Sohn, Y. Byun, J. Cho, J. Choe, K. Song, Development of the integrated methanol fuel processor using micro-channel patterned devices and its performance for steam reforming of methanol, International Journal of Hydrogen Energy 32, (2007) 5103 - 5108.

[18] J. Jang, C. Cheng, Y. Huang, C. Lee, C. Leu, Optimal design of parallel channel patterns in a micro methanol steam reformer, International Journal of Hydrogen Energy, 37 (2012) 16974-16985.

[19] E.V. Rebrov, J.C. Schouten, M.H.J.M deCroon, Single-phase fluid flow distribution and heat transfer in microstructured reactors, Chemical Engineering Science, 66 (2011) 13741393.

[20 ] J. Telotte, J. Kern, S. Palanki, Miniaturized methanol reformer for fuel cell powered mobile applications, International Journal of Chemical Reactor Engineering, 6 (2008) 6472. 
[21] A. Pattekar, M. Kothare, A radial microfluidic fuel processor, Journal of Power Sources, 147 (2005) 116-127.

[22] S. Sá, A. Mendes, J. Sousa, Ph.D Thesis: Methanol Steam Reforming for Fuel Cell Applications, FEUP-PDEQB, (2011).

[23] A. Karim, J. Bravo, A. Datye, Non isothermally in packed bed reactors for steam reforming of methanol, Applied Catalysis A: General, 282 (2005) 101-109.

[24] S. Samms, R. Savinell, Kinetics of methanol-steam reforming in a internal reforming fuel cell, Jornal of Power Sources 112 (2002) 13-29.

[25] Q. Li, J. Jensen, R. Savinell and N. Bjerrum, High Temperature Proton Exchange Membranes Based on Polybenzimidazoles for Fuel Cells, Progress in Polymer Science, 34 (2009) 449-447

[26] M. Geormezia, C. Chochosb, N. Gourdoupib, S.G. Neophytidesb, J. Kallitsisa, High performance polymer electrolytes based on main and side chain pyridine aromatic polyethers for high and medium temperature proton exchange membrane fuel cells, Journal of Power Sources, 196 (2011) 9382-9390

[27] M. Losey, M. Shmidt, K. Jensen, Micro-fabricated multiphase packed bed reactors: characterization of mass transfer and reaction, Industrial \& Engineering Chemistry Research, 40 (2001) 2555-2562.

[28] D. Mears, Diagnostic Criteria for heat transport limitations in fixed bed reactors, Journal of Catalysis 20 (1971) 127-131. 